\title{
A cross-sectional study on prevalence of bovine tuberculosis in Indian and crossbred cattle in Gangetic delta region of West Bengal, India
}

\author{
Ratan Das ${ }^{1}$, Premanshu Dandapat ${ }^{2}$, Arijit Chakrabarty², Pramod Kumar Nanda², Samiran Bandyopadhyay ${ }^{2}$ and \\ Subhasish Bandyopadhyay²
}

1. District Veterinary Hospital, Animal Resources Development Department, Government of Tripura, Ambassa, Dhalai, Tripura, India; 2. Eastern Regional Station, ICAR-Indian Veterinary Research Institute, Kolkata - 700 037, West Bengal, India.

Corresponding author: Premanshu Dandapat, e-mail: pdandapat@gmail.com

Co-authors: RD: drratan88@gmail.com, AC: arijit07chakrabarty@gmail.com, PKN: npk70@rediffmail.com, SB: samiranvet@gmail.com, SuB: subuicar@rediffmail.com

Received: 23-09-2017, Accepted: 18-12-2017, Published online: 16-01-2018

doi: 10.14202/IJOH.2018.1-7 How to cite this article: Das R, Dandapat P, Chakrabarty A, Nanda PK, Bandyopadhyay S, Bandyopadhyay S. A cross-sectional study on prevalence of bovine tuberculosis in Indian and crossbred cattle in Gangetic delta region of West Bengal, India. Int J One Health 2018;4:1-7.

\begin{abstract}
Aim: The aim of this study was to investigate the incidence of bovine tuberculosis (BTB), an old chronic disease having zoonotic potential, covering four districts in Gangetic delta region of West Bengal, India, and to find the prevalence in organized as well as backyard herds and variation in relation to their age, sex, and breeds.

Methods: The incidence of BTB in exotic and indigenous breeds of cattle $(n=173)$ of various age groups was investigated employing tuberculin (single intradermal tuberculin and comparative cervical tuberculin) tests and gamma interferon assay. Further, milk samples $(n=96)$ from milching animals and antemortem $(n=519)$ samples (nasal swab, buccal swab, and aspirates from pre-scapular lymph nodes) were also screened employing bacteriological and molecular techniques.

Results: In total, 36 (25.4\%) animals from organized and one (3.2\%) from backyard farming sector were found positive to BTB. Polymerase chain reaction (PCR) of milk samples based on 16S rRNA amplified the 1030 bp band in four samples indicating them belonging to genus Mycobacterium. Species-specific primers used to differentiate between Mycobacterium bovis and $M$. tuberculosis confirmed the presence of M. bovis. Prevalence of BTB in exotic crossbred animals (34.6\%) was significantly higher $(\mathrm{p}<0.001)$ compared to indigenous cattle $(10.5 \%)$. Further, gender-wise analysis of data with respect to BTB revealed higher positivity $(\mathrm{p}<0.05)$ among cows/heifers $(25.8 \%)$ compared to bulls/bullocks $(7.3 \%)$. Although BTBpositive cattle were detected in all the age groups, no statistical difference $(p=0.779)$ was found among them.
\end{abstract}

Conclusion: The findings indicate a higher prevalence of BTB in exotic crossbred animals in Gangetic delta and variation in breed susceptibility, thereby suggesting an urgent review of the present policy on adopting national crossbreeding program and implementation of "One Health" approach.

Keywords: bovine tuberculosis, cattle, India, prevalence, West Bengal.

\section{Introduction}

Bovine tuberculosis (BTB), caused by Mycobacterium bovis, is a highly prevalent infectious disease of cattle, buffaloes, and many wild species worldwide $[1,2]$. Due to its chronic and progressive nature, this disease causes a significant economic impact accounting $10-25 \%$ loss in productive efficiency in dairy cattle, often resulting in high morbidity in animals. The World Health Organization has also classified BTB as one of the seven neglected zoonotic diseases having a potential to infect human beings, either by consuming raw milk, meat, and their products [3] or inhaling infective droplets or direct contact with infected animals [4]. Being zoonotic in

Copyright: Das, et al. This article is an open access article distributed under the terms of the Creative Commons Attribution 4.0 International License (http://creativecommons.org/licenses/ by/4.0/), which permits unrestricted use, distribution, and reproduction in any medium, provided you give appropriate credit to the original author(s) and the source, provide a link to the Creative Commons license, and indicate if changes were made. The Creative Commons Public Domain Dedication waiver (http:// creativecommons.org/ publicdomain/zero/1.0/) applies to the data made available in this article, unless otherwise stated. nature, this disease also poses a significant public health problem, particularly in immunocompromised persons [5]. People living in rural areas are at higher risk as they usually share the same microenvironment and dwelling premises with animals. Although a direct correlation between $M$. bovis infection in cattle and the disease in human population has been well documented in developed countries, very little information is available from developing countries [6]. As per the latest reports available, 149,000 new human cases of zoonotic tuberculosis were detected globally in 2015, of which 13,400 deaths were due to $M$. bovis [4]. However, the above data may not truly represent the epidemiological status of human tuberculosis caused by $M$. bovis in India due to lack of effective disease surveillance, non-availability of more sensitive and specific diagnostic test, and effective reporting systems.

The most effective strategy for the control of BTB requires identification and removal of the infected animal from the herd. BTB is usually diagnosed based on delayed hypersensitivity reactions using various tuberculin tests such as single intradermal test (SIT), 
comparative intradermal, short thermal, and stormont tests. However, no single test can diagnose BTB at all stages of infection, as these tests have limitations on sensitivity and specificity [7]. To overcome this problem, animals are tested individually using comparative cervical tuberculin test (CTT) and gamma interferon $(\gamma$-IFN) assay alongside SIT to increase diagnostic sensitivity [8].

Keeping this in view, a cross-sectional study was conducted to find the most suitable antemortem tests out of tuberculin tests (SIT and CTT) and $\gamma$-IFN assay for screening of BTB in individual cattle and the variation in prevalence rate in relation to age, breed, and sex, covering four districts in Gangetic delta region of West Bengal.

\section{Materials and Methods}

\section{Ethical approval}

During this study, all animal handling procedures were performed following approved guidelines as laid down by the Institute Animal Ethics Committee.

\section{Study population}

A cross-sectional study was carried out to find the prevalence of BTB in cattle covering four districts, viz., Burdwan, Hooghly, Nadia, and South 24 Parganas in Gangetic delta region of West Bengal state.

A total of 173 (41 male and 132 female) cattle of different breeds in three age groups (1-5, 6-10 and 11-15 years) were selected for the study purpose. Other than non-descript animals (ND), the crossbred animals were Jersey cross (JC), Holstein-Friesian cross (HFC), Red Sindhi cross (RSC), Gir cross (GC), Sahiwal cross (SC), Jersey-Tharparkar cross (JTH), and Sahiwal-Tharparkar cross (STH). Of the 173 animals, 142 were from five organized farms and 31 were from four backyard farming sectors.

\section{In vivo single and comparative CTTs}

The SIT and CTT tests were conducted in animals $(n=173)$ following the protocol of the World Organization of Animal Health [9]. The tuberculin protein purified derivative (PPD) kits were procured from Prionics, the Netherlands. After measurement of the skin-fold thickness, bovine PPD tuberculin $(0.1 \mathrm{ml}$ containing $3000 \mathrm{IU} / \mathrm{dose})$ and avian PPD $(0.1 \mathrm{ml}$ containing $2500 \mathrm{IU} /$ dose) were injected intradermally in the center of the middle-third region in both sides of the neck avoiding the fine superficial capillaries. The skin-fold thickness of each injection site was re-measured after $72 \mathrm{~h}( \pm 6 \mathrm{~h})$ by vernier calipers to record the increment of skin-fold thickness, if any. The test results of the intradermal tuberculin tests were interpreted as per the OIE standards [9].

\section{In vitro $\gamma$-IFN test}

The release of $\gamma$-IFN cytokine in the blood of the cattle was determined by $\gamma$-IFN assay using commercially available bovine $\gamma$-IFN ELISA kit (BOVIGAM ${ }^{\circledR}$ assay) (Prionics, Switzerland) following the protocol of Wood and Jones [10]. Briefly, heparinized whole blood collected from the individual animal was stimulated with bovine and avian PPD antigens along with phosphate-buffered saline (PBS, $\mathrm{pH}$ 7.2) as control and incubated at $37^{\circ} \mathrm{C}$ for $18-24 \mathrm{~h}$. The $\gamma$-IFN present in the plasma supernatants was quantified in a sandwich ELISA following manufacturer's instructions. The blood plasma samples with stimulation by bovine PPD and having an OD value $(\geq 0.100)$ above that of avian PPD and nil antigen (PBS) indicated the presence of $M$. bovis infection.

The tuberculin tests (SIT and CTT) and $\gamma$-IFN assay in cattle were done simultaneously to ensure the reliability of the results as described elsewhere [11]. Based on the test results, the cattle positive to either SIT and $\gamma$-IFN assay or CTT and $\gamma$-IFN assay was interpreted as positive to BTB.

\section{Collection and processing of samples}

Antemortem samples $(\mathrm{n}=519)$ such as nasal swab, buccal swab, and aspirates from pre-scapular lymph node(s) were collected from all the animals $(\mathrm{n}=173)$. Besides, milk samples $(\mathrm{n}=96)$ were also collected from all the quarters of the udder of milching cattle. The samples were brought to the laboratory under cold chain for screening through bacteriological and molecular techniques.

\section{Cultural isolation of Mycobacterium spp.}

For cultural isolation of Mycobacterium spp., the antemortem samples were processed and decontaminated both by Petroff's sodium hydroxide method [12] and sulfuric acid method [13]. The processed samples were centrifuged at $1300 \mathrm{x} g$ for $15 \mathrm{~min}$, and the sediments were suspended in $3 \mathrm{ml}$ sterile physiological saline solution for inoculation. Before use, the slants were flooded with $2 \mathrm{ml}$ sterile physiological saline solution containing $5000 \mathrm{IU}$ of penicillin and $1 \mathrm{mg}$ of cycloheximide and allowed to stand for $10 \mathrm{~min}$ till excess fluid was poured off. All the samples were inoculated into Lowenstein-Jensen (LJ) with $0.5 \%$ $(\mathrm{w} / \mathrm{v})$ sodium pyruvate (LJ-P) and LJ with $2 \%$ glycerol (LJ-G) slants in duplicates. The slants were incubated at $37^{\circ} \mathrm{C}$ in an upright position up to 8 weeks and routinely observed for the growth of mycobacteria.

\section{Ziehl-Neelsen (ZN) staining}

For primary screening of the cultures grown on LJ media, ZN staining method was performed [14]. The smears were stained with carbol fuchsin and counter stained with $0.1 \%$ methylene blue and finally washed with water, dried, and observed under oil immersion (100X) lens.

\section{Genomic DNA extraction}

HiPurA $^{\mathrm{TM}}$ multi-sample DNA purification kit (HiMedia, India) was used for the extraction of genomic DNA from antemortem samples, cultural isolates (about $5 \times 10^{6}$ cells) as well as reference strains of mycobacteria (M. bovis AN5 and Mycobacterium tuberculosis $\mathrm{H} 37 \mathrm{Rv}$ ) in LJ media as per manufacturer's instructions. The genomic DNA was preserved 
in $100 \mu 1$ of elution buffer and stored at $-80^{\circ} \mathrm{C}$ until further use.

\section{Identification and molecular typing of Mycobacterium} spp.

The identification of Mycobacterium spp. in cultural isolates as well as tissue, swab, and milk samples was done by PCR following the protocol [15]. Further, amplification of a region of difference 9 (RD9) and $500 \mathrm{bp}$ fragments were also done to differentiate the presence of $M$. tuberculosis and M. bovis using the primers and thermal cycling conditions following the protocol of Das et al. [16]. The reference strains (M. bovis AN5 and $M$. tuberculosis $\mathrm{H} 37 \mathrm{Rv}$ ) were also run along with the samples for confirmation. A detailed account of the oligonucleotide primers used and PCR conditions maintained for confirmation of Mycobacterium spp. and M. tuberculosis complex is presented in Table-1 $[15,16]$. Amplified products were visualized and photographed under gel documentation system after electrophoresis in $1.5 \%(\mathrm{w} / \mathrm{v})$ agarose gel containing ethidium bromide $(0.5 \mu \mathrm{g} / \mathrm{ml})$ under $100 \mathrm{~V}$ for $1 \mathrm{~h}$ for bands of DNA of appropriate size.

\section{Statistical analysis}

Statistical analysis (descriptive and qualitative) was done using the Statistical Package for Social Statistics program version 20. Correlation coefficient, Chi-square, and Fisher's exact tests were used to establish relationships between the variables. The results were then presented using tables, besides narrative descriptions.

\section{Results}

All the antemortem samples ( $\mathrm{n}=519)$, namely, nasal swab, buccal swab, and aspirates from pre-scapular lymph nodes, collected from 173 cattle from organized and backyard farming system, tested negative for BTB by ZN staining as well as cultural isolation. However, of 96 milk samples, sediments from three were found positive by $\mathrm{ZN}$ staining, whereas two milk samples, processed by Petroff's sodium hydroxide method, were found positive for characteristic dysgonic, non-pigmented, and off-white mycobacterial colonies on LJ-P. The cultural isolates checked by ZN staining were also found positive.
DNA isolated from tissue samples as well as reference strains of mycobacteria (M. bovis AN5, M. tuberculosis $\mathrm{H} 37 \mathrm{Rv}$ ) was amplified by PCR based on 16S rRNA, $500 \mathrm{bp}$ fragment, and RD9 region. All antemortem samples including nasal swab, buccal swab, and aspirates from pre-scapular lymph nodes tested negative for BTB. The processing of milk samples $(\mathrm{n}=96)$ by PCR amplified the $1030 \mathrm{bp}$ band in 4 milk samples, indicating that they belong to genus Mycobacterium. Further, the samples tested for species-level identification using specific primers yielded a 500 bp fragment (Figure-1) and 206 bp product (Figure-2), while none were positive for $333 \mathrm{bp}$ for RD9 region, thereby confirming these as M. bovis.

The screening of cattle by SIT, CTT, and $\gamma$-IFN assay for the diagnosis of BTB is presented in Table-2. Of 173 cattle tested by both SIT and CTT on an individual basis, $108(62.4 \%)$ cattle tested positive. On the other hand, test results of $65(37.6 \%)$ cattle were found as doubtful and negative by SIT in comparison to $87(50.3 \%)$ positive and $86(49.7 \%)$ under

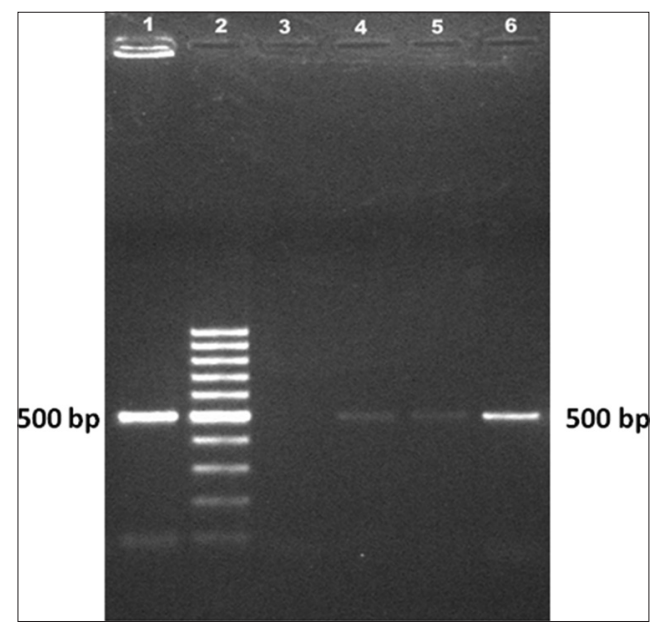

Figure-1: $1.5 \%$ agarose gel stained with ethidium bromide showing amplification of 500 bp fragment (Mycobacterium bovis specific) from positive milk samples indicating the presence of $M$. bovis. Lane 1: M. bovis AN5 (positive control); Lane 2. 100 bp Marker; Lane 3. Negative control; Lane 4. ND/1639; Lane 5. ND/1935; Lane 6. ND/1754.

Table-1: Details of primers and thermal cycling condition for identification of Mycobacterium species and Mycobacterium tuberculosis complex.

\begin{tabular}{|c|c|c|c|c|c|}
\hline Genes & $\begin{array}{l}\text { Primer } \\
\text { name }\end{array}$ & Primer $\left(5^{\prime}-3^{\prime}\right)$ sequence & $\begin{array}{l}\text { Amplicon } \\
\text { size (bp) }\end{array}$ & PCR condition & References \\
\hline \multirow[t]{2}{*}{ 16S rRNA } & MYCGEN-F & AGAGTTTGATCCTGGCTCAG & 1030 & $\begin{array}{c}94^{\circ} \mathrm{C} 5 \mathrm{~min}, 39 \times \\
\left(94^{\circ} \mathrm{C} 30 \mathrm{~s}, 62^{\circ} \mathrm{C} 3 \mathrm{~min}, 75^{\circ} \mathrm{C} 3 \mathrm{~min}\right) \\
75^{\circ} \mathrm{C} 7 \mathrm{~min}\end{array}$ & {$[15]$} \\
\hline & MYCGEN-R & TGCACACAGGCCACAAGGGA & & & \\
\hline \multirow[t]{3}{*}{ RD9 } & RD9F & GTGTAGGTCAGCCCCATCC & $333 / 206$ & $\begin{array}{c}95^{\circ} \mathrm{C} 5 \mathrm{~min}, 35 \times \\
\left(95^{\circ} \mathrm{C} 1 \mathrm{~min}, 54^{\circ} \mathrm{C} 1 \mathrm{~min}, 72^{\circ} \mathrm{C} 1 \mathrm{~min}\right) \\
72^{\circ} \mathrm{C} 10 \mathrm{~min}\end{array}$ & {$[16]$} \\
\hline & RD9I & CAATGTTTGTTGCGCTGC & & & \\
\hline & RD9R & GCTACCCTCGACCAAGTGTT & & & \\
\hline \multirow{2}{*}{$\begin{array}{l}500 \mathrm{bp} \\
\text { fragment }\end{array}$} & JBF & TCGTCCGCTGATGCAAGTGC & 500 & & \\
\hline & JBR & CGTCCGCTGACCTCAAGAAG & & & \\
\hline
\end{tabular}


inconclusive and negative category by CTT. The test results of $\gamma$-IFN assay conducted in samples from 173 cattle interpreted $41(23.7 \%)$ animals positive and $132(76.3 \%)$ as negative. The samples from cattle positive to $\gamma$-IFN assay were also positive to SIT, except four (4) interpreted as inconclusive. Based on the criteria of case definition, a total of 37 (21.4\%) cattle were interpreted as true positive (Table-2), and of them, $36(25.4 \%)$ were from organized farms and one $(3.2 \%)$ from backyard farming system. The correlation between positive and negative results of

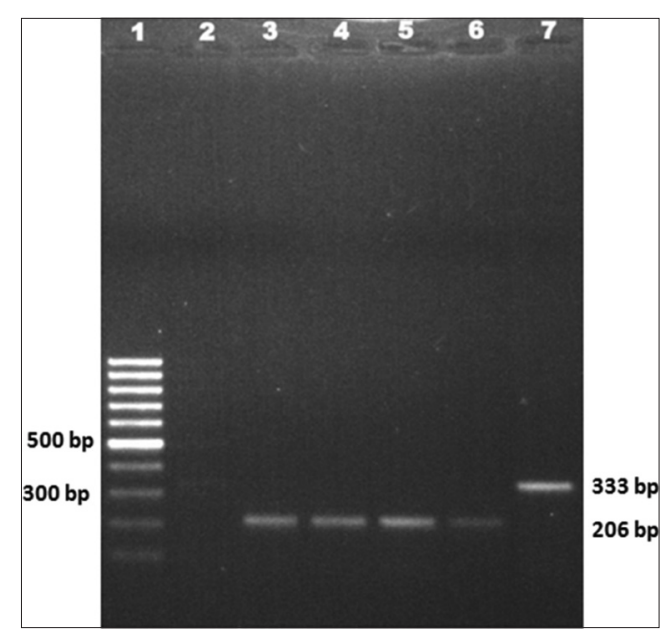

Figure-2: $1.5 \%$ agarose gel stained with ethidium bromide showing the amplification of RD9 region (206-bp). Lane 1: 100 bp DNA marker; Lane 2: Negative control; Lane 3: Positive control (Mycobacterium bovis AN5); Lane 4: ND/1639; Lane 5: ND/1935; Lane 6: ND/1754; Lane 7: Positive control (Mycobacterium tuberculosis $H_{37} R_{v}$ ).
SIT, CTT, and $\gamma$-IFN assay was found to be highly significant $(p \leq 0.001)$. The analysis of data on the prevalence of BTB in exotic cross and indigenous breeds of cattle is presented in Table- 3 .

In exotic cross (JC, HFC, and JTH), the prevalence of BTB $(34.6 \%)$ was found to be significantly higher $(\mathrm{p}<0.001)$ compared to indigenous cattle ( $\mathrm{SC}$, $\mathrm{ND}, \mathrm{GC}, \mathrm{RSC}$, and $\mathrm{STH})(10.5 \%)$. On further analysis of data on the prevalence of BTB in crossbred cattle (Table-4), it was found that JC (43.9\%) and JTH (44.4\%) were more susceptible compared to HFC $(17.9 \%)$. It was further observed that the rate of BTB prevalence in organized farms ranged from 18 to $61 \%$ (data not shown).

Gender-wise distribution of animals and their variation with respect to the prevalence of BTB is presented in Table-5. On data analysis, it was found to be statistically significant $(\mathrm{p}<0.05)$ with higher positivity among cows/heifers (25.8\%) compared to bulls/bullocks $(7.3 \%)$.

Further, the incidence of BTB in cattle of various age groups (1-5, 6-10, and 11-15 years) was studied and presented in Table- 6 . Although BTB-positive cattle were detected in all age groups, there was no significant statistical variation $(\mathrm{p}=0.779)$ among them.

\section{Discussion}

The present study was carried out to find the prevalence of BTB using different tests in different cattle breeds (indigenous or native cattle and crossbreds) in organized and backyard farms covering four districts in Gangetic delta of West Bengal. In total, 37

Table-2: Results of single intradermal tuberculin test, comparative cervical tuberculin test, and gamma interferon assay for the diagnosis of bovine tuberculosis.

\begin{tabular}{|c|c|c|c|c|}
\hline \multirow[t]{2}{*}{ Tests } & \multicolumn{2}{|c|}{ Final diagnosis } & \multirow{2}{*}{$\begin{array}{c}\text { Total } \\
\mathrm{n}=173(\%)\end{array}$} & \multirow[t]{2}{*}{ p value } \\
\hline & $\begin{array}{c}\text { Negative } \\
n=136(\%)\end{array}$ & $\begin{array}{c}\text { Positive } \\
n=37(\%)\end{array}$ & & \\
\hline \multicolumn{5}{|c|}{ Single intradermal tuberculin test } \\
\hline Positive & $72(52.9)$ & $36(97.3)$ & $108(62.4)$ & $<0.001^{*}$ \\
\hline Doubtful/negative & $64(47.1)$ & $1(2.7)$ & $65(37.6)$ & \\
\hline Total & $136(78.6)$ & $37(21.4)^{\#}$ & $173(100)$ & \\
\hline \multicolumn{5}{|c|}{ Comparative cervical tuberculin test } \\
\hline Positive & $53(39.0)$ & $34(91.9)$ & $87(50.3)$ & $<0.001 *$ \\
\hline Doubtful/negative & $83(61.1)$ & $3(8.1)$ & $86(49.7)$ & \\
\hline \multicolumn{5}{|c|}{ Gamma interferon assay } \\
\hline Positive & $4(2.9)$ & $37(100)$ & $41(23.7)$ & $<0.001^{*}$ \\
\hline Negative & $132(97.1)$ & 0 & $132(76.3)$ & \\
\hline
\end{tabular}

"Bovine tuberculosis positive from organized farms 36 (25.4\%) and 1 (3.2\%) from backyard farm. *Highly significant $(p<0.001)$.

Table-3: Prevalence of bovine tuberculosis in different breeds of cattle in West Bengal.

\begin{tabular}{|c|c|c|c|c|}
\hline \multirow[t]{2}{*}{ Cattle breed } & \multicolumn{2}{|c|}{ Final diagnosis } & \multirow[t]{2}{*}{ Total (\%) } & \multirow[t]{2}{*}{ p value } \\
\hline & Negative (\%) & Positive (\%) & & \\
\hline Exotic cross (JC, HFC, and JTH) & $51(65.4)$ & $27(34.6)$ & $78(100)$ & $<0.001^{*}$ \\
\hline Indian indigenous (SC, ND, GC, RSC, and STH) & $85(89.5)$ & $10(10.5)$ & $95(100)$ & \\
\hline Total & $136(78.6)$ & $37(21.4)$ & $173(100)$ & \\
\hline
\end{tabular}

*Significant, Chi-square test. JC=Jersey cross, HFC=Holstein-Friesian cross, RSC=Red Sindhi cross, GC=Gir cross, $\mathrm{SC}=$ Sahiwal cross, JTH=Jersey-Tharparkar cross, STH=Sahiwal-Tharparkar cross 
Table-4: Prevalence of bovine tuberculosis in different exotic crossbred cattle in West Bengal.

\begin{tabular}{|c|c|c|c|c|}
\hline \multirow[t]{2}{*}{ Cattle breed } & \multicolumn{2}{|c|}{ Final Diagnosis } & \multirow[t]{2}{*}{ Total (\%) } & \multirow[t]{2}{*}{ p value } \\
\hline & Negative (\%) & Positive (\%) & & \\
\hline $\mathrm{HFC}$ & $23(82.1)$ & $5(17.9)$ & $28(100)$ & $<0.001^{*}$ \\
\hline $\mathrm{JC}$ & $23(56.1)$ & $18(43.9)$ & $41(100)$ & \\
\hline JTH & $5(55.6)$ & $4(44.4)$ & $9(100)$ & \\
\hline Total & $51(65.4)$ & $27(34.6)$ & $78(100)$ & \\
\hline
\end{tabular}

*Significant, Chi-square test. HFC: Holstein-Friesian cross, JC: Jersey cross, JTH: Jersey-Tharparkar cross

Table-5: Gender-wise prevalence of bovine tuberculosis in cattle in West Bengal.

\begin{tabular}{lcccc}
\hline Gender & \multicolumn{2}{c}{ Final diagnosis } & Total (\%) & p value \\
\cline { 2 - 4 } & Negative (\%) & Positive (\%) & & $<0.012 *$ \\
\hline Female & $98(74.2)$ & $34(25.8)$ & $132(100)$ & \\
Male & $38(92.7)$ & $3(7.3)$ & $11(100)$ & \\
Total & $136(78.6)$ & $37(21.4)$ & $173(100)$ & \\
\hline
\end{tabular}

*Significant, Chi-square test

Table-6: Prevalence of bovine tuberculosis in cattle of different age groups.

\begin{tabular}{|c|c|c|c|c|}
\hline \multirow[t]{2}{*}{ Age in years } & \multicolumn{2}{|c|}{ Final diagnosis } & \multirow[t]{2}{*}{ Total (\%) } & \multirow[t]{2}{*}{ p value } \\
\hline & Negative (\%) & Positive (\%) & & \\
\hline $1-5$ & $64(81.0)$ & $15(19.0)$ & 79 (100) & 0.779* \\
\hline $6-10$ & $62(76.5)$ & $19(23.5)$ & $81(100)$ & \\
\hline $11-15$ & $10(76.9)$ & $3(23.1)$ & $13(100)$ & \\
\hline Total & $136(78.6)$ & $37(21.4)$ & $173(100)$ & \\
\hline
\end{tabular}

*Non-significant, Fisher's Exact test

animals were found positive to BTB, of which 36 were from organized farms and one from backyard farming system with a prevalence rate of $25.4 \%$ and $3.2 \%$, respectively. In India, several workers have reported a high prevalence of BTB in organized farms. In a comparative study, Mukherjee [17] reported a prevalence of tuberculosis in two dairy herds at $15.76 \%$ (Northern India) and $0.65-1.85 \%$ (Western India), while Thakur et al. [18] recorded $14.31 \%$ (overall animal prevalence) and $16.67 \%$ (farm prevalence) in Himachal Pradesh. In southern states of India such as Tamil Nadu and Karnataka, the rate of prevalence was $34.58 \%$ and $30-35 \%$, respectively [19]. Such a wide variation in prevalence of BTB could be due to breed type, screening tests used, management practices followed in the farming system, contact between animals of the same or different herds sharing common facilities, and grazing areas. [20].

The intradermal tuberculin test is recognized by both the OIE and the European Commission as a primary screening test for detection of tuberculosis in cattle [8]. However, confirmatory test for BTB is still a challenge since available diagnostic tools have limitations on sensitivity and specificity and no single test can diagnose BTB at all stages of infection [7]. In the present study, positivity of cattle to BTB using different screening tests (SIT, CTT, and $\gamma$-IFN assay) ranged from $23.7 \%$ to $62.4 \%$. Various studies have been carried out to evaluate the sensitivity and specificity of tuberculin tests (SIT and CTT) in cattle using different antigens under various epidemiological conditions [21]. Aranaz et al. [22] suggested that infection with M. avium subsp. paratuberculosis is regarded as interference factor in the diagnosis of bovine TB using PPDs. In general, the CTT test shows a higher specificity than the SIT test in detriment of the sensitivity, since it can distinguish animals infected with non-tuberculous mycobacteria or those vaccinated against paratuberculosis $[21,22]$ The variation in test results using SIT, CTT, and $\gamma$-IFN assays might be due to exposure of infected animals to other sensitizing mycobacteria [23] or prevalence of $M$. avium subsp. paratuberculosis as reported recently in the study area by this group of authors [24]. However, the sensitivity and specificity were found to be higher in $\gamma$-IFN assay than both the intradermal tests (SIT and CTT) which are in corroboration with the previous studies $[25,26]$.

M. tuberculosis has been reported in cattle by several researchers in India [27]. In fact, RD9 region is present in M. tuberculosis, while this region is absent in M. bovis and M. bovis BCG strains [16]. PCR amplification of some RD can distinguish between $M$. bovis and M. tuberculosis [28]. Besides, $500 \mathrm{bp}$ fragment has also been reported to be $M$. bovis specific, located at 3' end of the putative gene called RvD1-Rv2031c [29]. Therefore, in this study, it was presumed that either M. tuberculosis or M. bovis would be present in milk and other antemortem samples. Of 96 milk samples, two were positive for cultural isolation, whereas sediments from four milk samples were confirmed by $206 \mathrm{bp}$ and $500 \mathrm{bp}$ fragments in PCR assay for the presence of $M$. bovis. However, the reference strain 
of M. tuberculosis $\mathrm{H} 37 \mathrm{Rv}$ yielded a product of $333 \mathrm{bp}$ which showed the presence of RD9 region. From this, it is concluded that screening of raw milk samples simultaneously by PCR and cultural isolation can be performed to confirm BTB in cows.

The prevalence of BTB was significantly higher in organized farms with more exotic or crossbred animals (JC, HFC, and JTC) compared to indigenous breeds. The findings on breed susceptibility to BTB corroborates with the observations reported earlier by different researchers. Sharma et al. [30] concluded that Indian breeds were less affected by BTB than pure European breeds such as Jersey, Holstein, Friesians, and Brown-Swiss. Ameni et al. [1] demonstrated the breed level difference of cattle in susceptibility to BTB and indicated that Bos indicus cattle are more resistant than B. taurus. Thakur et al. [18] also reported higher positivity in JC and HFC breeds in Himachal Pradesh, India. The host genetics and its variation could be the reason for susceptibility to BTB in European breeds as reported by researchers [31].

The role of gender, if any, on incidences of BTB in cattle population was studied. A significant difference $(p=0.012)$ in incidences of BTB between genders was noticed in female animals $(25.8 \%)$ showing higher prevalence compared to male $(7.3 \%)$. Higher positivity in a female may be due to their maintenance in the same herd for several years as also reported earlier [32]. On the other hand, the introduction of mechanization in agriculture may have lowered the incidences of BTB in bullocks in eastern India, as farmers no longer rear them for years.

The risk of tuberculosis is highly age-dependent in human beings. However, limited data are available on age-dependent risks in cattle. BrooksPollock et al. [33] reported age-specific incidences with highest rates of infection in cattle aged between 12 and 36 months. Thakur et al. [18] recorded higher incidence of BTB in cattle above 6 years age, whereas Moiane et al. [34] recorded that animals older than 4 years are more likely to be infected and vulnerable to BTB compared to young ones. In the present study, although incidences of BTB in cattle of various age groups (1-5, 6-10, and 11-15 years) varied, there was no statistically significant difference among them.

The key issues that prevent to understand the true burden of zoonotic BTB in an animal population are the absence of systematic surveillance and lack of standard laboratory techniques in diagnosing M. bovis infection. From this study, it can be deduced that prevalence of BTB is mostly restricted to organized farms with more incidences in female and crossbred European cattle breeds in Gangetic delta region of West Bengal. Based on the sensitivity, SIT is recommended for screening of herds, whereas for individual cattle, both CTT and $\gamma$-IFN assays may be considered as methods of choice to maximize the detection of TB-infected animals, as they exhibit higher sensitivity, specificity, and accuracy. However, for confirmatory diagnosis, a battery of tests including CTT, $\gamma$-IFN assay, and screening of milk by PCR is recommended. As incidences of BTB are high in crossbred exotic cattle, highly productive indigenous germplasm may be considered for crossbreeding program. The detection of live zoonotic mycobacteria in milk is a cause of concern from a public health point of view. To overcome this problem, pasteurization of milk followed by boiling is strongly recommended before human consumption. To minimize the burden of BTB in cattle and its further spread to the human population, an effective national program involving "One Health" approach is required to combat this re-emerging disease.

\section{Authors' Contributions}

RD and PD conceived and designed the study. $\mathrm{RD}, \mathrm{AC}$ and SB carried out sampling and laboratory analysis. PKN and SuB analyzed and interpreted the data. All authors read and approved the final manuscript.

\section{Acknowledgements}

The authors are thankful to the Director, ICAR-IVRI, Izatnagar (Uttar Pradesh) for providing necessary research facilities for carrying out the study. Funds received from the Indian Council of Agricultural Research under Outreach Program on Zoonotic Diseases vide No.1-20/2014-PIM are duly acknowledged.

\section{Competing Interests}

The authors declare that they have no competing interests.

\section{References}

1. Ameni G, Aseffa A, Engers H, Young D, Gordon S, Hewinson G, et al. High prevalence and increased severity of pathology of bovine tuberculosis in Holsteins compared to zebu breeds under field cattle husbandry in central Ethiopia. Clin Vaccine Immunol 2007;14:1356-61.

2. Le Roex N, Koets AP, Van Helden PD, Hoal EG. Gene polymorphisms in African buffalo associated with susceptibility to bovine tuberculosis infection. PLoS One 2013;8:E64494.

3. Malama S, Muma JB, Godfroid J. A review of tuberculosis at the wildlife-livestock-human interface in Zambia. Infect Dis Poverty 2013;2:13.

4. Zoonotic TB. World Health Organization; 2016. Available from: http://www.who.int/tb/zoonoticTB.pdf?ua=1. Last accessed on 12.09.2017

5. O'Reilly LM, Daborn CJ. The epidemiology of Mycobacterium bovis infections in animals and man: A review. Tuber Lung Dis 1995;76 Suppl 1:1-46.

6. Cosivi O, Meslin FX, Daborn CJ, Grange JM. Epidemiology of Mycobacterium bovis infection in animals and humans, with particular reference to Africa. Rev Sci Tech 1995; 14:733-46.

7. Bezos J, Alvarez J, Romero B, De Juan L, Dominguez L. Bovine tuberculosis: Historical perspective. Res Vet Sci 2014;97:S3-4.

8. Schiller I, Oesch B, Vordermeier HM, Palmer MV, Harris BN, Orloski KA, et al. Bovine tuberculosis: A review of current and emerging diagnostic techniques in 
view of their relevance for disease control and eradication. Transbound Emerg Dis 2010;57:205-20.

9. OIE. Manual of Standards for Diagnostic Tests and Vaccines. Bovine Tuberc. Paris: OIE; 2008. p. 683-97.

10. Wood PR, Jones SL, Bovigam TM: An in vitro cellular diagnostic test for bovine tuberculosis. Tuberculosis 2001;81:147-55.

11. Álvarez J, Perez A, Marqués S, Bezos J, Grau A, de la Cruz ML, et al. Risk factors associated with negative in-vivo diagnostic results in bovine tuberculosis-infected cattle in Spain. BMC Vet Res 2014;10:14.

12. Krasnow I, Wayne LG. Comparison of methods for tuberculosis bacteriology. Appl Microbiol 1969;18:915-7.

13. De Lisle GW, Havill PF. Mycobacteria isolated from deer in New Zealand from 1970-1983. N Z Vet J 1985;33:138-40.

14. Baron EJ, Finegold JS. Mycobacteria and other bacteria with unusual growth requirements. In: Bailey and Scott's Diagnostic Microbiology. $10^{\text {th }}$ ed. St. Louis: CV Mosby Co.; 2008. p. 714.

15. Wilton S, Cousins D. Detection and identification of multiple mycobacterial pathogens by DNA amplification in a single tube. PCR Methods Appl 1992;1:269-73.

16. Das S, Das SC, Verma R. Occurrence of RD9 region and $500 \mathrm{bp}$ fragment among clinical isolates of Mycobacterium tuberculosis and Mycobacterium bovis. Microbiol Immunol 2007;51:231-4.

17. Mukherjee F. Comparative prevalence of tuberculosis in two dairy herds in India. Rev Sci Tech 2006;25:1125-30.

18. Thakur A, Sharma M, Katoch VC, Dhar P, Katoch RC. A study on the prevalence of bovine tuberculosis in farmed dairy cattle in Himachal Pradesh. Vet World 2010;3:409-14.

19. Dhinakaran M, Rao VN, Nedunchellian S. Immunological Response in Tuberculin Reactor Cattle. In: Proceedings of the National Symposium on Recent Advances in Control of Diseases of Crossbred and Companion Animals. Mumbai, India: Konkan Krishi Vidyapeeth. Bombay Veterinary College, Department of Medicine; 1991.

20. Ameni G, Vordermeier M, Firdessa R, Aseffa A, Hewinson G, Gordon SV, et al. Mycobacterium tuberculosis infection in grazing cattle in central Ethiopia. Vet $\mathrm{J}$ 2011;188:359-61.

21. Coad M, Clifford DJ, Vordermeier HM, Whelan AO. The consequences of vaccination with the Johne's disease vaccine, Gudair, on diagnosis of bovine tuberculosis. Vet Rec 2013; 172:266.

22. Aranaz A, De Juan L, Bezos J, Alvarez J, Romero B, Lozano F, et al. Assessment of diagnostic tools for eradication of bovine tuberculosis in cattle co-infected with
Mycobacterium bovis and M. avium subsp. paratuberculosis. Vet Res 2006;37:593-606.

23. Monaghan ML, Doherty ML, Collins JD, Kazda JF, Quinn PJ. The tuberculin test. Vet Microbiol 1994;40:111-24.

24. Bhutediya JM, Dandapat P, Chakrabarty A, Das R, Nanda PK, Bandyopadhyay S, et al. Prevalence of paratuberculosis in organized and unorganized dairy cattle herds in West Bengal, India. Vet World 2017;10:574-9.

25. Wood PR, Corner LA, Rothel JS, Baldock C, Jones SL, Cousins DB, et al. Field comparison of the interferon-gamma assay and the intradermal tuberculin test for the diagnosis of bovine tuberculosis. Aust Vet J 1991;68:286-90.

26. Cagiola M, Feliziani F, Severi G, Pasquali P, Rutili D. Analysis of possible factors affecting the specificity of the gamma interferon test in tuberculosis-free cattle herds. Clin Diagn Lab Immunol 2004;11:952-6.

27. Srivastava K, Chauhan DS, Gupta P, Singh HB, Sharma VD, Yadav V, et al. Isolation of Mycobacterium bovis and M. tuberculosis from cattle of some farms in north Indiapossible relevance in human health. Indian $\mathrm{J}$ Med Res 2008;28:26.

28. Parsons LM, Brosch R, Cole ST, Somoskövi A, Loder A, Bretzel G, et al. Rapid and simple approach for identification of Mycobacterium tuberculosis complex isolates by PCR-based genomic deletion analysis. J Clin Microbiol 2002;40:2339-45.

29. Rodriguez JG, Mejia GA, Del Portillo P, Patarroyo ME, Murillo LA. Species-specific identification of Mycobacterium bovis by PCR. Microbiology 1995;141:2031-8.

30. Sharma AK, Vanamayya PR, Parihar NS. Tuberculosis in cattle: A retrospective study based on necropsy. Indian J Vet Pathol 1985;9:14-8.

31. Brotherstone S, White IM, Coffey M, Downs SH, Mitchell AP, Clifton-Hadley RS, et al. Evidence of genetic resistance of cattle to infection with Mycobacterium bovis. J Dairy Sci 2010;93:1234-42.

32. Dinka H, Duressa A. Prevalence of bovine tuberculosis in Arsi Zones of Oromia, Ethiopia. Afr J Agric Res 2011;6:3853-8.

33. Brooks-Pollock E, Conlan AJ, Mitchell AP, Blackwell R, McKinley TJ, Wood JL, et al. Age-dependent patterns of bovine tuberculosis in cattle. Vet Res 2013;44:97.

34. Moiane I, Machado A, Santos N, Nhambir A, Inlamea O, Hattendorf J, et al. Prevalence of bovine tuberculosis and risk factor assessment in cattle in rural livestock areas of Govuro district in the southeast of Mozambique. PLoS One 2014;9:e91527. 